\title{
Repensando produtivismo em gestão no (e a partir do) Brasil $^{1}$
}

\author{
Rethinking productivism in management in (and from) Brazil
}

Alexandre Faria ${ }^{2}$

Este ensaio tem como principal objetivo explorar algumas questões históricas, políticas, e internacionais que nos ajudam a compreender não somente os principais antecedentes e implicações do produtivismo acadêmico na área de gestão, mas também a provocar reflexões no (e a partir do) Brasil, com algum distanciamento do mundo euro-americano e de suas instituições, para o posicionamento de instituições e atores em relação a este importante fenômeno.

\section{Breve análise histórica da gestão}

Encontramos nos dias atuais um enorme volume de desenvolvimentos acadêmicos em gestão, publicados em diversos outlets e em diferentes cantos do mundo. Esse quadro contemporâneo não seria possível sem o advento da gestão científica e a construção da ciência da gestão nos EUA. O âmbito da "gestão" foi elevado ao nível de "gestão científica" a partir dos trabalhos de Frederick Taylor nos EUA - mais especificamente com a publicação de Principles of Scientific Management em 1911. Até então, segundo os proponentes e defensores da gestão científica, grande parte daquilo que um leigo em qualquer canto do mundo podia chamar de gestão vinha sendo praticada e avaliada de forma não científica.

A partir da construção da gestão científica nos EUA, diferentes tipos de práticas e conhecimentos que eram classificados como práticas e conhecimentos de "gestão" tiveram que ser renomeadas, ou reclassificadas como "má gestão". Como a maioria de outras áreas do conhecimento científico, a gestão científica representa parte de uma história local que se transformou em um desenho global (Mignolo, 2009). Por meio de um processo de cientificação da gestão, esta foi transformada primeiramente em um bem nacional nos EUA e, posteriormente, convertida em um bem universal.

Esse influente trabalho de Taylor teve apoio de diferentes instituições nos EUA, com base no argumento de que a gestão científica seria capaz de corrigir diversos problemas nacionais. Foi construído então o entendimento de que a boa gestão representa progresso e sucesso e que a má gestão representa atraso e subdesenvolvimento. Apesar de obstáculos poderosos e importantes, a gestão científica assumiu aos poucos

1 Uma versão deste artigo foi apresentada no Painel denominado "Produtivismo Científico", no Encontro Nacional de Ensino e Pesquisa (EnEPQ), 20-22 de novembro de 2011, João Pessoa - PB, Brasil.

2 PhD em Industrial and Business Studies pela Warwick Business School, Reino Unido e Pós-doutorado na Universidade Nova de Lisboa, Portugal; Professor Adjunto da Fundação Getulio Vargas. Endereço: EBAPE/FGV, Praia de Botafogo, 190 - 5ํandar, sala 523, Botafogo, CEP 22250-900, Rio de Janeiro - RJ, Brasil. E-mail: alex.faria@fgv.br 
o poder equivalente ao de uma lei geral, aplicada não somente aos EUA, mas em diferentes partes do mundo. Por diferentes razões, é muito pouco provável que o mesmo resultado seria alcançado se gestão científica fosse enunciada e construída em (e a partir de) um país menos desenvolvido.

A partir da publicação e difusão do trabalho de Taylor, muitas das práticas e conhecimentos que eram observados nos EUA e em outros cantos do mundo foram classificados como não científicos ou "empíricos". Em nome do progresso ou da eficiência (ou mesmo da civilização ou desenvolvimento), essas práticas "empíricas" e os conhecimentos correspondentes foram convertidos em "boa gestão" por meio da aplicação dos princípios da gestão científica. Em outras palavras, essas outras práticas e conhecimentos que eram observados em diferentes cantos do mundo foram rebaixados por um modo superior made in US - a gestão científica - e convertidos. Esta proposta se baseou no argumento universalista de que a "best management" (ou "a melhor gestão", análogo à noção de "best way" defendido por Henry Ford) era uma ciência verdadeira baseada em leis, regras e princípios que podia ser aplicada a todos os tipos de atividade humana (Taylor, 1911).

A partir da construção da gestão científica e da representação de que esta é superior a outros tipos de prática e conhecimento, passamos todos a entender que gestão made in US (em termos de práticas e de conhecimento) representa o melhor possível. Análises históricas menos conhecidas nos contam que a transformação ou conversão da gestão "empírica" em "gestão científica" e, em seguida, a constituição do âmbito da ciência da gestão estão relacionadas a processos políticos complexos que continuam sendo ignorados pela literatura de gestão (ver Locke, 1996). Por diferentes razões, as quais não serão tratadas aqui, esses processos políticos e o correspondente lado obscuro da gestão continuam sendo ignorados pela maioria dos acadêmicos da área. Como observamos em diferentes instâncias nos EUA, tais como o imperativo do publish or perish no contexto acadêmico, prevalecem no final das contas os argumentos de que "história é passado" e de que "o show tem que continuar".

A gestão científica ganhou um impulso extraordinário a partir da atribuição do êxito dos EUA na Segunda Guerra Mundial à boa gestão em grandes corporações. Em 1962, no início dos Anos Dourados, Alfred Chandler $\mathrm{Jr}$ - historiador que viria anos à frente ser aclamado como o pai da gestão estratégica - publicou então a obra Strategy and Structure: Chapters in the History of the Great Industrial Enterprise. Esta obra foi publicada seis anos após a publicação de The Power Elite, por C. Wright Mills. A análise histórica realizada por Chandler, publicada já no contexto da Guerra Fria, mostrava que as grandes corporações eram benignas e superiores a outros tipos de organização. A principal razão da superioridade dessas organizações não era o seu poder político-econômico relativo, mas sim a extraordinária capacidade de adequar suas estruturas e estratégias às demandas da sociedade e do mercado.

Segundo Chandler, as grandes corporações dos EUA se dedicavam ao desempenho de longo prazo - em oposição àqueles que argumentavam que grandes corporações detinham poderes excessivos e que isso impossibilitava a construção da democracia nos EUA - e ao mercado (o qual era tido por Chandler como livre) - em oposição àqueles que argumentavam que as grandes corporações e seus principais dirigentes manipulavam mercados e leis. Segundo aqueles que defenderam e promoveram o trabalho de Chandler, a extraordinária capacidade de transformação das grandes corporações era a principal explicação para a posição dos EUA como nação-líder no período pós-Guerra.

Por sua vez, o trabalho de Mills argumentava que os EUA eram governados por elites que ocupavam diferentes tipos de organização e que bloqueavam a construção da democracia no país. O livro de Mills descreve o complexo relacionamento entre as elites política, militar e econômica dos EUA e mostra que os membros dessas três instituições compartilhavam uma visão de mundo baseada em quatro pontos que se opunham frontalmente ao que viria a ser defendido por Chandler: (a) as elites seguiam uma definição militar da realidade, (b) as elites se viam como superiores e separadas do resto da sociedade, (c) as elites tinham capacidade de movimentação dentro e através das três estruturas institucionais, e (d) a socialização de novos membros dependia da capacidade de os mesmos reproduzirem os interesses e fundamentos dessas elites de poder. 
Diferentemente da incapacidade de Chandler em reconhecer o papel central exercido pelo complexo industrial militar inaugurado oficialmente pela administração do Presidente Eisenhower, Wright Mills ressaltava que a comunidade de interesses dessas elites era orientada pela "metafísica militar" - a qual transformava a economia em permanente economia de guerra e tinha nas grandes corporações e seus altos executivos importantes protagonistas desse processo - em franca oposição aos fundamentos de corporação livre e mercado livre mobilizados pelo trabalho de Chandler.

Esse quadro de disputas (inter)nacionais de ordem político-ideológica ajuda a explicar por que o lado obscuro da gestão científica e do imperativo do publish or perish continua sendo ignorado nos EUA. Por sua vez, meu argumento aqui é que essas questões são centrais para a condução de debates efetivos e realistas sobre produtivismo acadêmico em administração e contabilidade no Brasil. É pouco provável que uma análise desse tipo venha a ser conduzida pela comunidade acadêmica de gestão nos EUA e é virtualmente impossível que viesse a ser publicada naquele país.

Esse quadro de disputas (inter)nacionais explica tanto por que o trabalho de Mills tornou-se virtualmente ignorado (ou censurado) pela academia de gestão quanto por que o trabalho de Chandler tornou-se de crucial importância, em termos políticos, para a legitimação e internacionalização da área da gestão a partir dos EUA. O que estou dizendo é que não são apenas as disputas políticas entre áreas do conhecimento dentro dos EUA que explicam o não reconhecimento do trabalho de Mills pela ciência da gestão. Mais importante, havia também o contexto de política internacional da Guerra Fria influenciando e impulsionando a academia. Mills foi imediatamente classificado como comunista e seu trabalho foi tido como não científico por muitos de seus pares na academia. É importante ressaltar que o trabalho de Mills foi desenvolvido no contexto do Macartismo (em inglês, McCarthyism) - período de intensa patrulha anticomunista, perseguição política e desrespeito aos direitos civis nos EUA que se estendeu desde o fim da década de 1940 até meados da década de 1950. O medo do comunismo e da sua influência em instituições dos EUA tornou-se exacerbado. Esse termo foi cunhado para criticar as ações do senador americano Joseph McCarthy, tendo depois sido usado para nomear vários tipos de práticas e estratégias, não necessariamente ligadas às elaboradas por McCarthy.

De fato, na época da publicação de Strategy and Structure por Chandler, Mills estava marginalizado pela comunidade acadêmica dos EUA. O Presidente John Kennedy tinha lançado no ano anterior o programa Aliança para o Progresso. A Aliança para o Progresso (denominada de Alianza para el Progreso nos outros países da América Latina tinha como objetivo promover o desenvolvimento econômico mediante a colaboração financeira e técnica em toda a América Latina, a fim de não deixar surgir outro país com tendências aos ideais comunistas, como ocorrera em Cuba (a Revolução Cubana ocorreu em 1959). Além da ampliação de poderio militar na região, o governo dos EUA promoveu a construção de instituições científicas e de conhecimento acadêmico que se opusessem aos princípios comunistas. Nesse processo político-internacional contra o avanço do comunismo, uma das prioridades foi o fomento da área de gestão na região.

Esse quadro político-internacional afetou a área de gestão não apenas em países da América Latina, mas também nos EUA - resultando em um processo complexo de colonização epistêmica neste país que justifica a construção de análises críticas na América Latina, por exemplo, que ajudem a promover a descolonização da área (Mignolo, 2009). Análises históricas conduzidas por pesquisadores nos EUA apontam que a revolução gerencial atribuída por Chandler somente às grandes corporações ocorreu também no âmbito do governo dos EUA (Ferleger e Lazonick, 1993). Porém, a importância política da adequada "gestão" da dicotomia estado-mercado na academia no contexto da Guerra Fria ajuda a explicar por que um dos pais da gestão estratégica nos EUA foi incapaz de reconhecer que organizações do governo daquele país praticavam a "boa gestão" no âmbito da agricultura.

...the Managerial Revolution occurred not only in manufacturing as Alfred Chandler (...) and others have amply documented but also in agriculture. In manufacturing the managerial revolution occurred primarily (although not entirely) within private-sector enterprises that came to dominate their industries. In agriculture, the managerial revolution occurred 
primarily (although not entirely) within public-sector organizations that defined the strategies and structures of the developmental state (Ferleger e Lazonick, 1993, p. 70).

Esse quadro também ilustra como o processo de colonização epistêmica nos EUA levou à marginalização ou subordinação da área de administração pública. Esse quadro ficou ainda mais poderoso na segunda metade dos anos 1970, quando Chandler publicou The Visible Hand: The Managerial Revolution in American Business (1977). Nesta obra, que viria a receber o Prêmio Pulitzer na área de História em 1978, Chandler descreve o capitalismo gerencial construído dentro das grandes corporações industriais como superior não apenas ao capitalismo de mercado, mas também a outros tipos de capitalismo observados em economias avançadas. A obra descreve que a classe gerencial nos EUA, composta por indivíduos comuns - a despeito de classe, raça, origem ou crença -, é a responsável pelo capitalismo gerencial que se constituiu naquele país. Gerentes de grandes corporações são descritos como membros da classe que constitui a mão visível, em consonância com os pressupostos da doutrina de free market e free corporation e em franca oposição aos pressupostos do comunismo, que era tida por Chandler como mais eficiente do que a mão invisível proposta por Adam Smith.

Produtivismo científico não era uma questão tão central para acadêmicos da área de gestão naquela época como é hoje em dia. Entretanto, ampliar a produção acadêmica da área já era uma prioridade. A primeira razão era garantir a legitimação da área de gestão na sociedade dos EUA, em oposição a autores e membros da sociedade ou da política nacional que assumissem uma posição crítica - os quais eram imediatamente classificados como comunistas ou marxistas e, em seguida, marginalizados, mesmo que estivessem influenciados tão e somente por ideias liberais. Uma segunda razão é que a área de gestão e seus acadêmicos não detinham uma boa reputação no meio acadêmico; consequentemente as escolas de negócios não conseguiam atrair os maiores talentos. Por sua vez, a lógica dominante do Big Science nos EUA no período da Guerra Fria - modelo dominante de ciência conhecido também como Vanevar Bush Model - defendia o uso do talento científico de indivíduos e as capacidades e recursos de instituições acadêmicas e não acadêmicas para o atendimento de necessidades nacionais. Para ser beneficiada pelo framework do Big Science, a produção acadêmica em gestão no período da Guerra Fria deveria atender mais às questões nacionais dos EUA do que ao pressuposto liberal (traduzida por muitos acadêmicos de inclinação esquerdista como "autonomia") de produção de conhecimento pelo mero interesse de produzir conhecimento.

A área de gestão ganhou importância adicional no contexto do Big Science por ser capaz de bloquear outros tipos de conhecimento que pudessem levar países do Terceiro Mundo a grandes revoluções que afetassem a ordem internacional imposta pelos EUA e aliados. Com a justificativa de deter o avanço do comunismo, políticas externas dos EUA, focadas na gestão do Terceiro Mundo no período da Guerra Fria (ver Cooke, 2004), promoveram então estratégias internacionais baseadas no uso de recursos de força e coerção, por um lado, e de recursos de sedução e atração, por outro. Essas estratégias ajudam a explicar a efetiva disseminação de conhecimento científico de gestão, nos âmbitos de educação e pesquisa, para países do Terceiro Mundo e também por que as áreas de política, em geral, e de política internacional, de forma mais específica, foram excluídas do campo de gestão nos EUA (Faria e Guedes, 2010). A disseminação de conhecimento e instituições de gestão foi particularmente importante não apenas para projetar o poder dos EUA e, assim, evitar o avanço do comunismo em países do Terceiro Mundo, mas também para evitar que o campo da gestão em países e regiões correspondentes fosse pensado, praticado, e mobilizado por acadêmicos e sociedades sob uma perspectiva política.

Apesar do senso comum e do desprezo dos acadêmicos da área de gestão por análises históricas, argumento aqui que a história não deve ser tida como mero passado. Tampouco devemos nos subordinar ao argumento de que "o show tem que continuar". Ao contrário, argumento aqui que análises históricas são de central importância para a compreensão do contexto contemporâneo e moldagem do contexto no futuro. O que estou afirmando aqui é que questões de política (inter)nacional que são desprezadas ou suprimidas pela área são importantes não somente para a adequada compreensão do processo de construção da gestão científica e expansão da cientificação da gestão no contexto da Guerra Fria, mas também para debates atuais sobre produtivismo acadêmico em gestão no Brasil. 


\section{Entendendo gestão em uma era de globalização}

O inesperado e súbito final da Guerra Fria e o advento da globalização foram marcados pela maciça disseminação de conhecimento científico da área de gestão, em paralelo a um processo de transferência maciça de políticas e desenhos institucionais neoliberais a partir dos EUA, e de instituições multilaterais lideradas por esta potência. O bipolarismo da Guerra Fria, protagonizado pelos EUA e pela URSS, foi substituído pelo unipolarismo dos EUA, por um lado, e por outro lado, pelos anseios e discursos relacionados ao multipolarismo de mercado e ao mundo sem fronteiras (Layne, 2006). Com o suporte das políticas de reforma estabelecidas pelo Consenso de Washington, a globalização neoliberal foi então imposta politicamente em larga escala, apesar do significado dominante na literatura de gestão de que a globalização é meramente econômica e desprovida de questões políticas e ideológicas que marcaram o período da Guerra Fria - tudo de acordo com a controversa tese de fim da história proclamada por Francis Fukuyama.

Desde então o conhecimento da área de gestão tem sido de grande importância, por um lado, para o processo de conversão neoliberal em escala global impulsionada pelo Consenso de Washington; por outro lado, e curiosamente, o conhecimento da área tem sido atrativo para aqueles que advogam o multipolarismo no período pós-Guerra Fria. Evidentemente, os processos de imposição política e de conversão epistêmica em diferentes países e regiões têm sido marcados não apenas por mera "conversão" passiva, mas também por complexos processos de traduções e resistências em diferentes locais.

Após o final da Guerra Fria os EUA entraram em um período que a área de política internacional chama de momento unipolar. Com o ocaso do bipolarismo, os EUA surgiram como a única superpotência no contexto internacional, com inigualável poderio militar, em um mundo que aspirava pela substituição do biporalismo pelo multipolarismo. Esse quadro complexo e ambíguo ajuda a explicar por que foi construída e publicada a tese do Fim da História, de Francis Fukuyama, e também por que a Europa acelerou a construção de políticas focadas em equilíbrio de poder. Especialistas e autoridades concordavam que uma União Européia forte seria necessária para conter o risco de os EUA abraçarem com mais vigor o unipolarismo do que o multipolarismo.

Essa percepção de risco na Europa era também explicada pela constituição de uma teoria forte (i.e., neorrealismo) nos EUA no âmbito da política externa de que o advento do multipolarismo e a crescente interdependência entre estados-nação na era da globalização seriam mais problemáticos para a ordem global do que o próprio bipolarismo e a ameaça de um grande conflito nuclear haviam sido. $\mathrm{O}$ debate correspondente entre neo-liberais e neo-realistas tornou-se dominante no âmbito das relações internacionais; apesar disso, a área de gestão continuou comprometida fortemente com a corrente neoliberal, em detrimento do reconhecimento de que a realidade estava sendo moldada por uma complexa inter-relação entre as duas correntes (ver Faria et al., 2011). Ou seja, muitos daqueles que defendiam mercado livre e promoviam a construção de instituições multilaterais e eram classificados como afiliados à corrente neoliberal eram, em realidade, defensores da corrente neo-realista. Em outras palavras, muitos que defendiam o mercado livre e proclamavam o fim da política promoviam, nos bastidores, políticas internas e mecanismos de governança global que levavam à crescente militarização do país.

De fato, enquanto muitos sonhavam com um mundo multipolar governado pelas forças do mercado e pela paz mundial, os EUA e a Europa se prepararam para a gestão de um mundo de crescente desequilíbrio político e assimetrias internacionais. Segundo a perspectiva neo-realista - a qual pressupõe que o contexto internacional é uma anarquia na qual os estados soberanos estão em permanente disputa por poder político o mundo na era globalização seria marcado pela substituição do cenário da Guerra Fria por um cenário de inúmeras disputas e conflitos que seriam conduzidos em diferentes regiões, e com capacidade de difusão em escala global. Alguns especialistas argumentavam que a globalização tornava inevitável o choque das civilizações.

A corrente neoliberal e seus discursos não faziam muito sentido para autoridades (incluindo statepersons, policy-makers e business people) nos EUA e isso ajuda a explicar por que o poderio militar do país (hard 
power) se ampliou no período pós-Guerra Fria e também por que o país se concentrou em construir recursos e capacidades (com especial ênfase em conhecimento acadêmico e cultura) para seduzir e atrair o "resto" do mundo (soft power). Esse quadro ajuda a explicar a ascensão meteórica dos think tanks, organizações voltadas fundamentalmente para influenciar o âmbito de políticas, nos EUA e Europa.

Em termos de política internacional, a área de gestão e o argumento de que a área de política estava sendo definitivamente substituída pela de economia tornaram-se muito importantes para os propósitos de consumo externo. Autoridades (incluindo statepersons, policymakers, e business leaders) e dos EUA (e Europa) correram para anunciar para o mundo que o lado sombrio era parte da história, apoiadas pela tese de fim da história publicada por Fukuyama e amplamente difundidas pelas instituições do Consenso de Washington. Esse complexo processo de camuflagem que se fortaleceu após a ascensão do unilateralismo dos EUA ajuda a explicar não somente o extraordinário processo de expansão da área de gestão e de suas instituições no período pós-Guerra Fria, mas também, por outro lado, a necessidade da condução de debates sobre o produtivismo acadêmico no "resto" do mundo.

Também por causa da preocupação com o momento unipolar dos EUA, grandes potências da União Européia abraçaram a área de gestão como uma das prioridades acadêmicas para a região, apesar do preconceito histórico com relação a uma área que era classificada como inferior e tipicamente made in US. As escolas de negócio floresceram primeiramente no Reino Unido e, em seguida, em diversos outros países da região, em especial no bloco ex-comunista. Mesmo as universidades de Oxford e Cambridge, que durante décadas classificaram a área de gestão como uma área menor e tipicamente norte-americana, decidiram construir suas respectivas escolas de negócios no final dos anos 1990. Em paralelo, com base na justificativa de que era necessário conter o processo de neoamericanização da Europa, ilustrado pelo avanço das reformas do Consenso de Washington na região, diversas instituições "européias" de gestão foram criadas ou reforçadas.

A emergência dessas instituições européias na área de gestão, tais como a European Foundation for Management Development (EFMD) e a European Academy of Management (EURAM), é explicada então não apenas pelo processo de mercadização do sistema acadêmico que se verificou no contexto do neoliberalismo global. Ou seja, o processo de engajamento da Europa com a governança da gestão por meio da construção e fortalecimento de instituições especializadas não significa apenas que a academia passou a ser governada pelas forças do mercado. $\mathrm{O}$ engajamento europeu com a governança da gestão explicita a crescente importância política da área em uma era de globalização.

Os eventos de 11 de setembro em 2001 tornaram evidente a importância da corrente neo-realista para o futuro dos EUA e para a ordem global. Para especialistas em política externa dos EUA, os eventos de 11 de setembro mostram que o processo de conversão do mundo em escala global, o qual contava com a colaboração da área de gestão, não foi suficiente para a construção de um mundo melhor. Essa visão de mundo ajuda a explicar a ascensão do unilateralismo dos EUA e também a posição ambígua da Europa em relação a este fenômeno.

A partir dos eventos de 11 de setembro, as instituições de governança da área de gestão passaram a ser disputadas e divididas então entre EUA e Europa. Correspondentemente, e tendo questões de segurança como prioridade intransitiva pelas grandes potências, essas instituições foram mobilizadas para a projeção do poder euro-americano em diversos cantos do mundo. Os processos de internacionalização da Association to Advance Collegiations of Schools of Business (AACSB) e da EFMD em anos recentes, e a aparente disputa entre essas duas instituições ilustram este processo. Também ilustram esse processo o desenvolvimento, a promoção e a difusão acelerada dos rankings de classificação de produção acadêmica. É importante lembrarmos que em 6 de junho de 2002, o Presidente George W. Bush argumentou que "in the war against terrorism, America's vast science and technology base provides us with a key advantage". É correto afirmar que a construção de condições favoráveis, especialmente por meio de estruturas e mecanismos de governança específicos, para a difusão da ciência em escala global tornou-se prioritário, com o propósito de "deter e moldar crenças em países ou regiões menos desenvolvidas que foram associadas nos EUA ao 
terrorismo" (Faria e Guedes, 2010, p. 10). Esse quadro ajuda a explicar nossas preocupações no Brasil com o produtivismo na área de gestão.

\section{Produtivismo em gestão sob uma perspectiva de governança}

O campo euro-americano da gestão se fortaleceu de forma extraordinária e até mesmo surpreendente no período pós-Guerra Fria, não exatamente porque gestão passou a ser praticada e pesquisada com um nível de interesse sem precedentes por profissionais e acadêmicos em um mundo global e sem fronteiras. As seções anteriores mostraram que o processo de fortalecimento euro-americano não deve ser visto como um processo natural, ou analisado como um processo regido tão e somente pelas forças de mercado trazidas pela globalização neoliberal. O campo euro-americano de gestão se fortaleceu especialmente por causa da construção de instituições acadêmicas específicas e de estruturas e mecanismos de governança da área. Tais estruturas e mecanismos de governança forneceram condições para a projeção da influência da academia euro-americana em uma era de globalização marcada pela complexa relação entre visões de mundo e correntes de relações internacionais contraditórias. É importante ressaltar que a importância da produção e difusão do conhecimento acadêmico em gestão e a construção e internacionalização de estruturas e mecanismos euro-americanos de governança da área ficaram particularmente importantes para a ordem global após os eventos de 11 de setembro e a consequente ascensão do unilateralismo dos EUA.

Por causa disso, ao mesmo tempo em que observamos competição entre instituições da Europa e dos EUA, observamos também a constituição de redes e mecanismos de cooperação entre os dois lados do Atlântico. Um dos exemplos desse quadro de ambiguidade no âmbito da governança é o êxito alcançado pela construção e difusão em escala global da "acreditação tripla", liderada pela AACSB, EFMD e Association of MBAs (AMBA). Em paralelo à meteórica ascensão dos think tanks no período pós-Guerra Fria, essas instituições têm exercido um papel central para o êxito do amplo processo de ocidentalização que se acentuou a partir dos eventos de 11 de setembro.

A área de gestão tem uma trajetória de relativa independência, em comparação com outras áreas do conhecimento mais estabelecidas, no que diz respeito à submissão a estruturas nacionais ou regionais de governança ou regulação. Essa característica histórica da área é paradoxalmente explicada pela baixa reputação acadêmica da mesma desde seus primeiros e modestos passos nos EUA. Por essa e outras razões já exploradas neste ensaio, a área de gestão é uma das mais adequadas para a construção de uma estrutura supranacional (i.e., euro-americana) de governança que permita a ascensão de sociedades inteiras por meio do conhecimento ocidental. Essa tem sido uma das principais preocupações dos usuários e mantenedores do sistema euro-americano de rankeamento das publicações acadêmicas. A SCImago, em parceria com a Scopus e a Elsevier, tem publicado com entusiasmo estudos e dados estatísticos que mostram o número crescente de publicações acadêmicas (incluindo gestão) em países de tradição muçulmana, e também o número crescente de citações de autores e periódicos do mundo euro-americano por autores daqueles países.

De fato, a gestão geopolítica do conhecimento acadêmico ficou proeminente nas agendas internacionais a partir dos eventos de 11 de setembro e ainda mais relevante a partir da construção do temor político nos EUA e na Europa com relação ao avanço das economias emergentes, em especial a China. Tendo em vista a posição do país dentro do grupo das economias emergentes, essa última questão é de central importância não somente para a construção de debates críticos no (e a partir do) Brasil sobre o produtivismo na área de gestão, mas também para a internacionalização de análises locais para o mundo euro-americano.

A área de gestão tem importância crucial na gestão geopolítica contemporânea do conhecimento acadêmico. Assim como no caso de milhões de pessoas nos EUA com capacitação acadêmica modesta que obtiveram grau de mestrado acadêmico com validade universal a partir da construção e proliferação de programas de MBA naquele país, e com isso ajudaram a deslocar a posição europeia de superioridade acadêmica (ou eurocentrismo) no âmbito da sociedade do conhecimento que se constituiu no período pós-Guerra Fria, 
governos nacionais reconheceram a importância da área de gestão para promover a rápida ascensão de suas sociedades no contexto do capitalismo acadêmico ou da sociedade de conhecimento que se constituiu no período pós-Guerra Fria. Programas de MBA promovem a rápida conversão de "massas iletradas" em "exército de mestres". No caso da China, por exemplo, a oferta de programas de MBA em larga escala não somente acelerou o processo de ocidentalização desejado, como também ajudou a elevar o poder relativo de seus cidadãos e representantes oficiais nos círculos de poder em diferentes cantos do mundo em uma era de globalização.

As instituições euro-americanas que constituem a chamada acreditação tripla foram exitosas ao estabelecer a parte visível da governança da área de gestão em escala global e, ademais, ajudar a ocultar as dimensões políticas e internacionais da governança da área. Em paralelo, também foram exitosas as instituições de rankeamento de escolas de negócios e as que governam o impacto das publicações acadêmicas. Essas instituições não seriam tão exitosas em outras áreas do conhecimento acadêmico. Elas vêm sendo capazes não apenas de estabelecer a ordem esperada, mas também de moldar as estruturas e os mecanismos de governança que estão sendo construídos ou aperfeiçoados em outros países ou regiões. Esse quadro ilustra o meu argumento de que a área de gestão tornou-se mais importante no período pós-Guerra Fria do que no período da Guerra Fria, em termos políticos e internacionais, apesar do menosprezo dos acadêmicos da área e de instituições de governança local pelas questões que sustentam este argumento.

Neste sentido, meu argumento principal neste ensaio é de que o longo processo de construção da governança da área, liderada por instituições euro-americanas, é de fundamental importância para debates sobre o produtivismo acadêmico na área de gestão no (e a partir do) Brasil e também para a construção de reflexões críticas acerca das posições a serem assumidas por instituições e indivíduos no país e no exterior.

A extraordinária profusão da área de gestão em uma era de globalização complexa foi acompanhada e sustentada pela construção de estruturas e instituições euro-americanas de governança e difusão em escala global. Análogo ao processo de cientificação da gestão iniciado no século passado, a difusão de gestão para outros mundos implicou na construção de estruturas e mecanismos euro-americanos de governança que classificam quem deve ser incluído ou não pela área e medem a posição hierárquica de países, instituições e indivíduos. É pouco provável que esse aparato euro-americano venha a classificar negativamente instituições euro-americanas e interesses correspondentes. Por outro lado, é provável que esse aparato acentue o poder euro-americano de intervenção internacional por meio do argumento de que potências que detêm liderança na área de gestão estão mais capacitadas a liderar a gestão de problemas complexos e globais, tais como mudança climática e pobreza, por meio de intervenções de soft power em países menos desenvolvidos e economias emergentes.

Neste sentido gostaria de chamar a atenção para o caso europeu. Na Europa, o histórico de ceticismo e resistência à área de gestão made in US durante a Guerra Fria foi substituído por um complexo processo de submissão, engajamento seletivo, e tradução. O processo de americanização da Europa resultou não apenas na expansão internacional da área de gestão made in US, especialmente junto aos países ex-comunistas, com o suporte das reformas promovidas pelo Consenso de Washington, mas também a emergência de processos de engajamento seletivo com a gestão made in US por meio de processos de tradução. Esse amplo processo de tradução na Europa tornou-se particularmente importante não apenas para a internalização da área de gestão, mas também para a internacionalização da "gestão européia" para diversos cantos do mundo, em especial para ex-colônias, como alternativa ao modelo dominante made in US.

Esse processo de engajamento da Europa com a área de gestão foi beneficiado pela ascensão do unilateralismo dos EUA. De fato, após os eventos de 11 de setembro, a difusão do conhecimento científico em escala global passou a ser tratada como elemento fundamental para a segurança dos EUA, a partir da associação do conhecimento religioso ao fundamentalismo e ao terrorismo. Esse processo foi acompanhado pelo uso da força militar (especialmente no que diz respeito à invasão do Iraque), pelo afastamento dos EUA das instituições multilaterais, e pela ascensão do antiamericanismo (fora e dentro dos EUA). 
De fato, há um entendimento atual nos EUA de que a liderança isolada do país em diversas áreas do conhecimento acadêmico representa um obstáculo para combater o contexto de antiamericanização que se estabeleceu como resposta ao avanço do unilateralismo dos EUA. Política externa dos EUA entende que a efetividade do conhecimento acadêmico como recurso de soft power exige a atenuação da liderança acadêmica dos EUA em relação a outros países, bem como a atenuação do domínio ocidental em relação ao oriente. Em outras palavras, por questões de segurança nacional, tornou-se necessário o reconhecimento da voz do "outro" no campo acadêmico. Na área de gestão, esse movimento de engajamento com o "outro" (ou com o "resto" do mundo) tornou-se mais mobilizável após a construção e difusão de estruturas e instituições euro-americanas de governança da área.

Esse quadro ajuda a explicar a difusão acelerada das instituições e organizações euro-americanas de gestão em diversos países e regiões. Podemos destacar, por exemplo, a construção do African Academy of Management pela (US) Academy of Management. Além disso, cabe destacar a realização do Academy of Management Global Conference na África do Sul em 2012 pela (US) Academy of Management, com o propósito de elevar a capacidade de compreensão e intervenção de acadêmicos e instituições dos EUA em economias emergentes. Também podemos destacar a criação do Latin American European Meeting on Organization Studies (LAEMOS), iniciativa do European Group for Organisation Studies (EGOS), que terá sua quarta edição no México, em 2012, a inauguração do primeiro programa de MBA em Cuba pelo EFMD e pelo ESADE (Barcelona) em outubro de 2011, e a realização do Colóquio do EGOS pela primeira vez na América - mais especificamente em Montreal - em 2013. Além disso, cabe destacar a crescente presença e influência de organizações euro-americanas de acreditação - notadamente a AACSB e o EFMD - no Brasil e em outros países da América Latina.

Gostaria, entretanto, de ressaltar que processos geopolíticos mais ousados estão em curso, referentes ao processo de substituição do produtivismo medido pelo impacto das publicações por um produtivismo medido pelo impacto social e político produzido por instituições acadêmicas da Europa - em outras palvras, o Research Assessment Exercise (RAE) será substituído pelo Research Excellence Framework (REF) em 2014 (http://www.hefce.ac.uk/research/ref/). No Reino Unido, já está em vigor a política que diz que universidades serão pagas em função do impacto da pesquisa de seus acadêmicos, não mais apenas pela qualidade. $\mathrm{O}$ documento oficial, produzido pelo governo, informa que a pesquisa acadêmica produzida no Reino Unido tem que produzir impactos tanto nacional quanto internacionalmente. A distinção entre instituições acadêmicas e think tanks está cada vez menos clara, em parte explicado pela ascensão meteórica dos think tanks chineses nos últimos anos e pela crescente preocupação euro-americana com os avanços das economias emergentes no cenário global.

\footnotetext{
"Impacts will be assessed in terms of their 'reach and significance' regardless of the geographic location in which they occurred, whether locally, regionally, nationally or internationally. The UK funding bodies expect that many impacts will contribute to the economy, society and culture within the UK, but equally value the international contribution of UK research". (REF 2014, 2011, p. 27) [grifo nosso]
}

Por esta razão, concluo o presente ensaio argumentando que no futuro breve teremos saudades dos problemas causados pelo produtivismo acadêmico medido por citações. A priorização oficial do impacto "real" no Reino Unido - já usual nos EUA, apesar da aparente ausência de influência estatal no âmbito acadêmico naquele país - e no resto da Europa, por meio do impact toolkit divulgado pelo Economic and Social Research Council (ESRC), sugere que uma nova onda de intervenções "reais" via academia euroamericana de gestão (com um tipo de soft power) ocorrerá em países menos desenvolvidos e economias emergentes.

Trata-se de momento oportuno para estabelecermos no Brasil, e a partir do Brasil, um debate esclarecedor sobre os antecedentes e as implicações históricas, políticas e internacionais deste importante fenômeno sob uma perspectiva "outra", que seja capaz de descolonizar a área de gestão e desafiar, em nome da pluriversidade do conhecimento e da multipolaridade mundial, a liderança euro-americana. 
Inspirado na perspectiva descolonial desenvolvida por Walter Mignolo, concluo meu argumento com uma pergunta dirigida a instituições (em especial, mas não somente, à Anpad) e acadêmicos no Brasil: afinal, qual será a nossa posição (ou nossas posições) em relação a este importante fenômeno?

And once upon a time scholars assumed that if you 'come' from Latin America you have to 'talk about' Latin America; that in such a case you have to be a token of your culture. Such expectation will not arise if the author 'comes' from Germany, France, England or the US. As we know: the first world has knowledge, the third world has culture, Native Americans have wisdom, Anglo Americans have science (Mignolo, 2009:1) [grifo nosso]

\section{Referências}

Chandler, A. Strategy and Structure: Chapters in the history of the American industrial enterprise. Cambridge: Massachusetts Institute of Technology Press, 1962.

1977.

The Visible Hand: the managerial revolution in American business. Cambridge: Havard University Press,

Cooke, B. The Managing of the (Third) World. Organization, v.11, n. 5, 2004. p.12-25.

Faria, A.; Guedes, A. (Eds.). International Management and International Relations: a Critical Perspective from Latin America. New York: Routledge, 2010.

E. Ibarra-Colado, and A. Guedes. Internationalization of management, neo-liberalism and the Latin America challenge. Critical Perspectives on International Business, v. 6, n. 2/3, 2010. p. 97-115.

Ferleger, L; Lazonick, W. The Managerial Revolution and the Developmental State: The Case of U.S. Agriculture. Business and Economic History, v. 22, n. 2, 1993. p. 67-98.

Fukuyama, F. The End of History and the Last Man. New York: Free Press, 1992.

Impact toolkit do ESRC. Disponível em: <http://www.esrc.ac.uk/funding-and-guidance/tools-and-resources/impacttoolkit/index.aspx>. Acesso em: 16 dez. 2011.

Layne, C. The Unipolar Illusion Revisited. International Security, v. 31, n. 2, Fall 2006. p. 7-41.

Locke, R. The Collapse of the American Management Mystique. Oxford: Oxford Press, 1996.

Mignolo, W. Epistemic Disobedience, Independent Thought and De-Colonial Freedom. Theory. Culture \& Society, v. 26, n. 7-8, 2009. p. 1-23.

Mills, C. The Power Elite. Oxford: Oxford Press, 1956.

Taylor, F. The Principles of Scientific Management. New York: Harper Bros., 1911. p.5-29 .

Research Excellence Framework (REF). Disponível em: <http://www.hefce.ac.uk/research/ref/>. Acesso em: 16 dez. 2011. 